\title{
MEMORANDUM
}

No 06/2014

\section{Education and Cancer Risk}

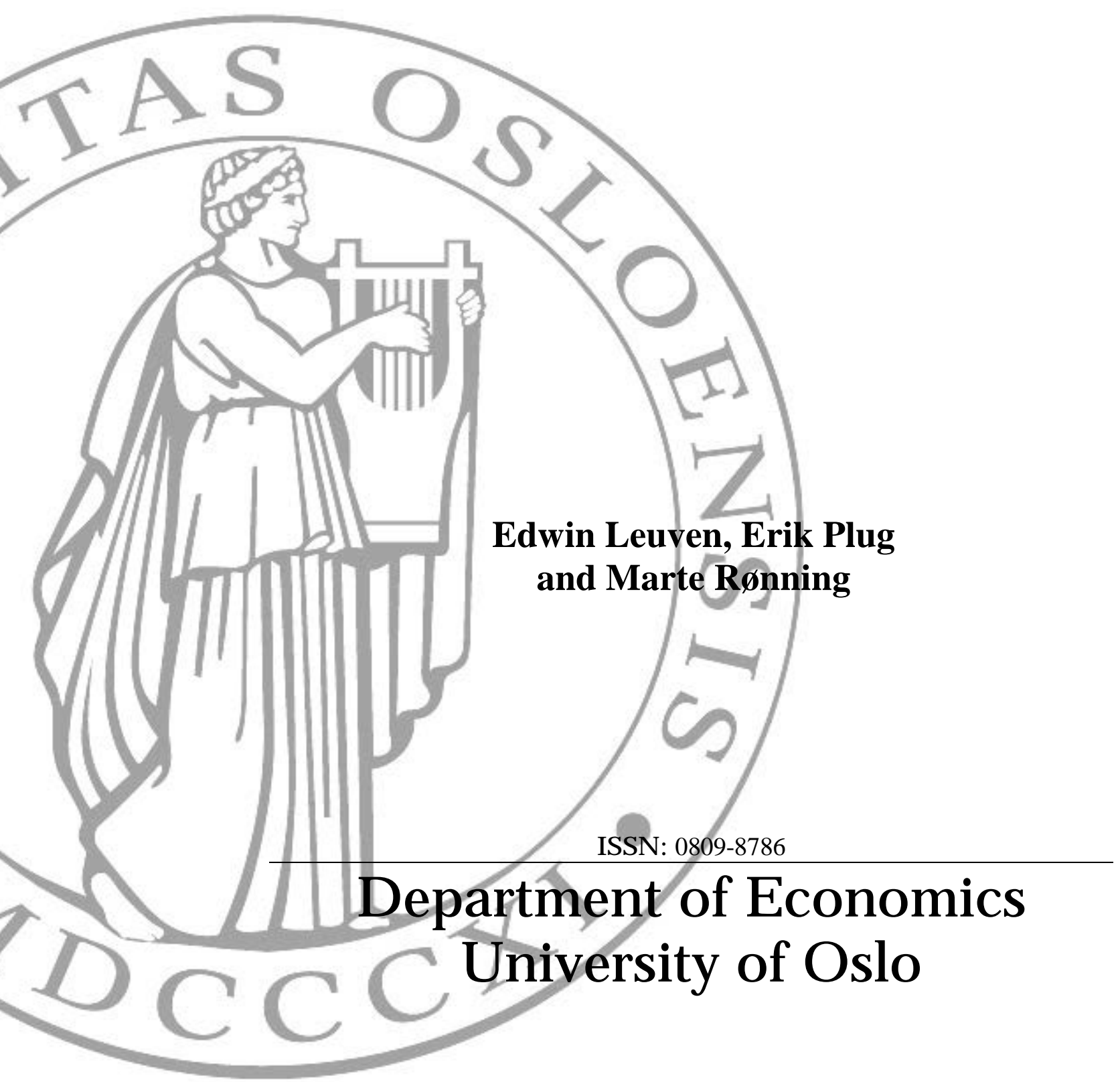


This series is published by the

\section{University of Oslo \\ Department of Economics}

P. O.Box 1095 Blindern

N-0317 OSLO Norway

Telephone: + 4722855127

Fax: $\quad+4722855035$

Internet: http://www.sv.uio.no/econ

e-mail: $\quad$ econdep@econ.uio.no
In co-operation with

The Frisch Centre for Economic

Research

Gaustadalleén 21

N-0371 OSLO Norway

Telephone: $\quad$ +4722958820

Fax: $\quad$ +4722958825

Internet: $\quad$ http://www.frisch.uio.no

e-mail: $\quad$ frisch@frisch.uio.no

\section{Last 10 Memoranda}

\begin{tabular}{|c|c|}
\hline No $05 / 14$ & $\begin{array}{l}\text { Edwin Leuven, Erik Plug and Marte Rønning } \\
\text { The Relative Contribution of Genetic and Environmental Factors to Cancer } \\
\text { Risk and Cancer Mortality in Norway }\end{array}$ \\
\hline No $04 / 14$ & $\begin{array}{l}\text { Tone Ognedal } \\
\text { Morale in the Market }\end{array}$ \\
\hline No $03 / 14$ & $\begin{array}{l}\text { Paolo Giovanni Piacquadio } \\
\text { Intergenerational Egalitarianism }\end{array}$ \\
\hline No $02 / 14$ & $\begin{array}{l}\text { Martin Flatø and Andreas Kotsadam } \\
\text { Drought and Gender Bias in Infant Mortality in Sub-Saharan Africa }\end{array}$ \\
\hline No $01 / 14$ & $\begin{array}{l}\text { Yngve Willassen } \\
\text { Optimal Migration and Consumption Policies over an Individual's Random } \\
\text { Lifetime }\end{array}$ \\
\hline No $28 / 13$ & $\begin{array}{l}\text { Olav Bjerkholt } \\
\text { Promoting Econometrics through Econometrica 1933-37 }\end{array}$ \\
\hline No $27 / 13$ & $\begin{array}{l}\text { Trygve Haavelmo } \\
\text { Variations on a Theme by Gossen }\end{array}$ \\
\hline No $26 / 13$ & $\begin{array}{l}\text { Halvor Mehlum } \\
\text { Samfunnsøkonomiens plass i jussen - Det juridiske fakultets første hundre } \\
\text { år. }\end{array}$ \\
\hline No 25/13 & $\begin{array}{l}\text { Halvor Mehlum } \\
\text { Samfunnsøkonomiens plass i jussen - Det juridiske fakultets første hundre } \\
\text { år. }\end{array}$ \\
\hline No $24 / 13$ & $\begin{array}{l}\text { Eric Nævdal and Jon Vislie } \\
\text { Resource Depletion and Capital Accumulation under Catastrophic Risk: } \\
\text { Policy Actions against Stochastic Thresholds and Stock Pollution }\end{array}$ \\
\hline
\end{tabular}

Previous issues of the memo-series are available in a PDF® format at: http://www.sv.uio.no/econ/english/research/memorandum/ 


\title{
Education and cancer risk*
}

\author{
Edwin Leuven ${ }^{\dagger} \quad$ Erik Plug ${ }^{\ddagger} \quad$ Marte Rønning§
}

\section{Memo 06/2014-v1}

(This version February, 2014)

\begin{abstract}
There exists a strong educational gradient in cancer risk, which has been documented in a wide range of populations. Yet relatively little is known about the extent to which education is causally linked to cancer incidence and mortality. This paper exploits a large social experiment where an education reform expanded compulsory schooling during the 1960s in Norway. The reform led to a discontinuous increase in educational attainment, which we exploit to estimate the effect of the reform on various cancer outcomes. Our main finding is that education has little if any impact on cancer risk. This holds for all cancer sites together as well as the most common cancer sites in isolation, with two exceptions. The compulsory school reform lowered the risk of lung cancer for men, but increased the risk of colorectal cancer for women.
\end{abstract}

Keywords: Education, Causality, Health, Cancer

JEL-Codes: I12, I21

*We are grateful to Kjell Gunnar Salvanes for generously sharing the details of the education reform. The research on this paper was funded by the Norwegian Research Council. Some of the data in this article are from the Cancer Registry of Norway. The Cancer Registry of Norway is not responsible for the analysis or interpretation of the data presented.

†University of Oslo. Also affiliated with CEPR, CESifo, ESOP, IZA and Statistics Norway. E-mail: edwin.leuven@econ.uio.no

$\ddagger$ University of Amsterdam. Also affiliated with TIER, Tinbergen Institute, IZA and UCLS. E-mail: e.j.s.plug@uva.nl

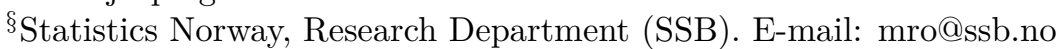




\section{Introduction}

Cancer is a primary health risk. Over the last 30 years, the western world (including Norway) has witnessed a steady increase in cancer incidence and cancer mortality (for almost all cancer sites), for both men and women. By now, cancer is one of the major causes of death, and this is unlikely to change in the near future. On a brighter note, considerable progress in cancer survival has been made for many of the common cancer sites. Due to improved cancer prevention as well as cancer treatment, we have also seen an increase in cancer survival rates, which more than doubled in most western countries for most (but not all) cancer sites over the same period.

Nowadays, there are many public policies that aim to reduce cancer risks and increase cancer survival; among these are public health campaigns to encourage healthy behavior, taxation and subsidization to regulate healthy consumption, mandatory screening programmes to detect cancer early, health insurance policies to improve access and coverage, financial assistance programmes to cancer patients, and the funding of cancer research. Each policy has its benefits and costs. Economists can potentially inform this debate, but this requires a sound empirical strategy to empirically test the effectiveness of such policies.

In this paper we consider education as a promising means to reduce cancer risk. Education is malleable and possibly important. In fact, we believe that the postwar rise in education in most western countries can partly account, at least in theory, for the observed patterns in cancer risk, which apparently move in opposite directions. To understand why this is, we rely on two basic cancer facts. First, cancer incidence and cancer mortality rise almost exponentially with age (DePinho 2000). If more educated men and women live longer lives, we should see that higher levels of education lead (in the long run) to a rise in cancer incidence and cancer mortality. Supportive evidence includes the work of Lleras-Muney (2005), which shows that more educated men and women indeed live longer because of more education (and 
not because of something else). Second, cancer incidence and cancer mortality fall with improved cancer prevention and treatment. If more educated men and women have more resources to devote to preventive and curative health care, prefer longer and healthier lives, are abler to detect cancer early, and are better informed on how to seek and respond to the cancer treatments, we should see reduced cancer risks (and higher survival rates) among more educated men and women. Along similar lines, Grossman (2006) and Cutler and Lleras-Muney (2010) argue that differences in resources, preferences and knowledge may explain why more educated men and women face lower health risks.

In this paper we concentrate on the question whether education reduces cancer risk, zoom in on middle aged men and women, and try to establish whether more educated men and women face lower cancer risks because of more education, and not because of something else. In order to get at the causal link between education and cancer risk empirically, we need an exogenous education shock. An education reform, which expanded compulsory schooling during the 1960s in Norway, offers such opportunity to identify and estimate the effect of education on cancer risk. From 1960 to 1972, this education reform was gradually implemented in different municipalities at different times. Before the reform, children had to attend school through the 7th grade. After the reform, children had to attend school through 9th grade, adding two years of compulsory education (among others). Since the reform exogenously affected school choices, these children form meaningful control and treatment groups; that is, some children experienced two extra years of education compared to children similar to them on any other point but their birth year, and municipality of residence. In our empirical setup, we will follow these children into (later) adulthood and subsequently compare their differences in cancer mortality, overall cancer risk and cancer risks for the most common cancer sites. ${ }^{1}$

\footnotetext{
${ }^{1}$ With cancer data available up to 2007, we can follow reform affected children until they are somewhere between 50 and 61 years old. Middle aged men and women form, we think, the appropriate age group to potentially find a negative effect of education on cancer risks, driven by educational differences in resources, preferences and knowledge. Middle aged men and women are,
} 
The data we use are a combination of multiple administrative registers in Norway. Education information comes primarily from the 1970 Census. $^{2}$ Educational attainment is measured in nominal years of education taken from detailed education classifications. Municipality information comes from the 1960 Census, which collects information on municipality of residence at the time of the education reform. Cancer information comes from the Norwegian Cancer Registry, which holds records of any cancer diagnosis and, in case of death, whether cancer has been the leading cause. These registers are then matched using personal identification numbers of all Norwegian citizens, providing information about a child's year of birth, gender, municipality, educational attainment, cancer mortality, overall cancer risk and cancer risks for all cancer sites.

To preview the main results, we find that education has little, if any, impact on cancer risk. This holds for all cancer sites together as well as the most common cancer sites in isolation, with two exceptions. Our estimates consistently show that the education reform lowered the risk of lung cancer for men, but increased the risk for colorectal cancer for women. Equally important is our finding that almost all the associations we estimate between education, cancer mortality and cancer risk, aggregated across all cancer sites, are statistically significant and negative. It thus seems that unobserved endowments play a crucial role in explaining the educational gradient in cancer risk.

Our work contributes to a large medical literature on the socioeconomic determinants of cancer risk and cancer survival. Most of these cancer studies compare cancer incidence, cancer survival and cancer mortality at several cancer sites across groups with different education and socioeconomic backgrounds. Without a claim on completeness, we refer to three recent and representative cancer studies (and the references therein), each linking education to one particular cancer domain. On however, too young to detect any positive effect of education on cancer mortality, realized at the end of the extended life span.

${ }^{2}$ The Norwegian Education Registry started in 1970; we therefore collect education information from this registry for those who completed their education after 1970. 
cancer incidence, Mouw et al. (2008) estimate the relationship between education and cancer risk in the United States and obtain significantly negative associations at most (but not all) cancer sites. ${ }^{3}$ On cancer survival, Hussain et al. (2008) investigate how survival time after the first cancer diagnose varies by education using Swedish cancer registries. They report primarily significant and positive associations. And on cancer mortality, Albano et al. (2007) use mortality data drawn from the United Stated and find that education (measured in years) is strongly and negatively associated with mortality at all cancer sites. Although the main message taken from all these (but also other) studies indeed suggests that education may be helpful in reducing cancer risk and increasing cancer survival, we should be careful in interpreting cancer associations. Thus far, the medical literature has not established whether the relationship on education and cancer risk, cancer survival and cancer mortality is causal.

Our work also contributes to a growing literature in economics on the causal link between education and later life health, using comparable sources of exogenous variation in education. The first causal study on education and mortality is of Lleras-Muney (2005). She uses differences in compulsory schooling laws across the various states in the United States as her source of exogenous variation in educational attainment and finds that education has a causal impact on mortality; that is, more education increases life expectancy. ${ }^{4}$ Since then, other studies have examined comparable relationships using changes in compulsory schooling legislation, across regions, time or both, to determine whether education is helping us to be healthier (Clark and Royer 2010; Oreopoulos 2006; Meghir et al. 2012) . The results of these studies are mixed. Oreopoulos (2006) shows that more educated men have a better

\footnotetext{
${ }^{3}$ The exceptions are prostate and skin cancer for men, and breast and skin cancer for women. These positive associations are commonly found in most other cancer studies on education and cancer risk, including our study.

${ }^{4} \mathrm{~A}$ recent study by Buckles et al. (2013) considers the impact of college education on cancer mortality among US men. They exploit the widespread notion that young men in the Vietnam-era were more inclined to enroll in college to lower their risk of being drafted for military service. With military draft lotteries in the 70s as their main instrument for college education, they find large protective effects on cancer mortality (and on lung cancer mortality in particular).
} 
health and live longer, while Clark and Royer (2010) report that education has little impact on later life health. The findings of Meghir et al. (2012) lie somewhere in between. Their estimates indicate that more educated men and women experience reduced mortality up to the age of fifty, but that these life gains are offset by increased mortality later on in life. Meghir et al. (2012) also consider cancer mortality as some of their health outcomes, which makes their study most closely related to our work. They find no impact of the Swedish compulsory school reform on cancer mortality at all cancer sites (but the lung). But they do find that more educated men and women face lower mortality rates in preventable diseases (which they define as lung cancer and cirrhosis of the liver). While their results on cancer mortality are very similar to the results we obtain in our work, which is reassuring in a literature as sparse as this, we should stress that our work is also very different because of its explicit cancer focus; that is, we estimate the causal link between education, cancer risk and cancer mortality, where we look at all cancer sites together as well as the most common cancer sites in isolation.

The rest of our paper proceeds as follows. Section 2 describes the Norwegian education reform in more detail. Section 3 introduces the empirical strategy and shows how the reform can be used to get differences-in-differences estimates on the effect of education on cancer risk. Section 4 describes that rest of the data set. Section 5 presents results. And Section 6 concludes.

\section{The compulsory school reform in Norway}

In this paper we exploit an education reform that, among others, expanded compulsory schooling in Norway. The education reform in Norway has been used before to identify the causal effect of education on, for example, child education (Black et al. 2005) or fertility (Monstad et al. 2008), and its institutional background has been well documented in studies of, for example, Lie (1973) and Lindbekk (1993). In the following, we build on these sources to provide a brief overview of the reform, and 
how the reform can be helpful in identifying the effect of education on cancer risk.

\subsection{Institutional background of the compulsory school reform}

In the 1960s and 1970s, an education reform extended compulsory education from seven to nine years. Prior to the reform, children started school at the age of 7 and finished compulsory schooling in 7th grade at the age of 14. After the reform, children started school again at the age of 7 but finished compulsory schooling in 9 th grade at the age of 16 . The educational reform also introduced a new comprehensive school. In the new comprehensive school children were kept together in one common school through 9th grade. All children were exposed to the same curriculum and faced the same level of instruction in two subsequent tracks: grades 1 to grades 6 , which are regarded as lower primary education, and grades 7 to 9 , which are regarded as upper primary. The new comprehensive school replaced the more selective system of lower secondary education where children were tracked into two parallel tracks with different levels of instruction: the academic track (realskole) prepared children for an academic gymnasium and subsequent university education and the vocational track (continuation school) prepared children for vocational training and general education outside the path to higher professional and theoretical education. The reform was aimed to improve the quality of primary education in particular the rural areas. This was done by establishing a common primary school act where the local governments of cities and rural communities were subject to the same minimum school requirements regarding course of instruction, school facilities et cetera.

The reform was implemented within a twelve year period. The reform came to start in 1960. The first cohort that could be affected by the reform was the cohort born in 1947. These children started school in 1954 and were exposed to the reform for at least two years. The reform was completed in 1972. The last cohort affected was the cohort born in 1958. In Figure 1 we plot cohort shares of reform exposed children by birth cohort. The figure illustrates the gradual roll out of the reform. 


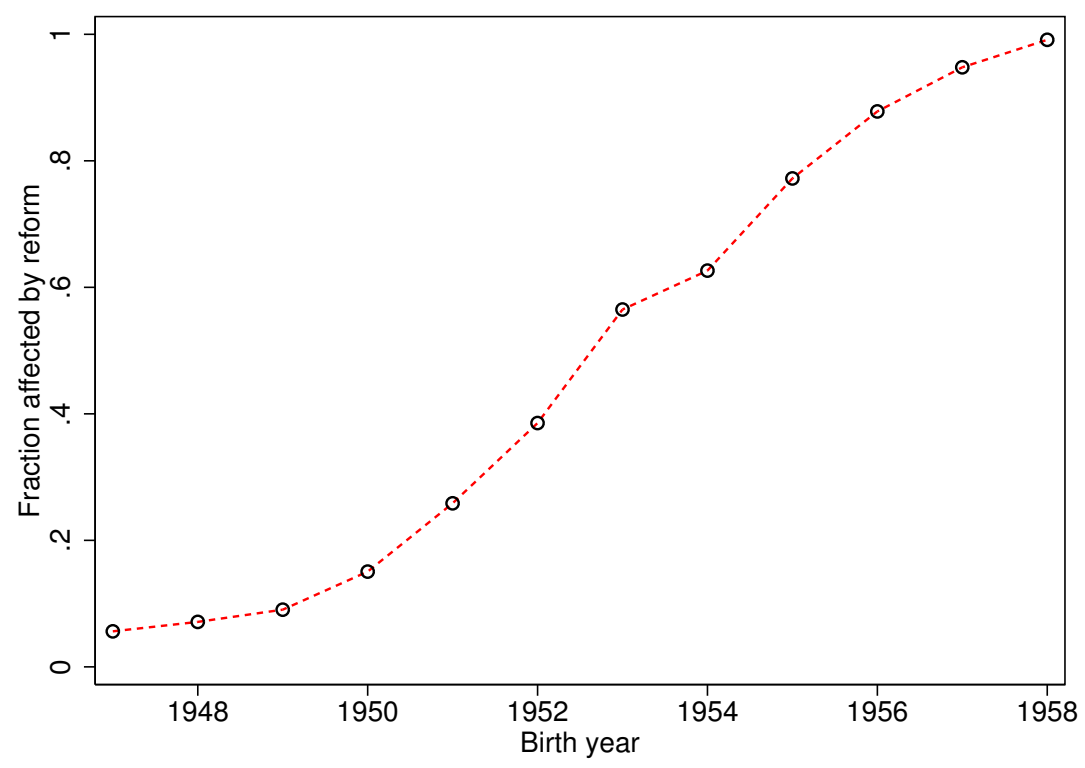

Figure 1. Cohort shares of reform exposed children by birth cohort.

Prior to implementation, municipalities were asked to report on their population growth, tax revenues, on the local demand for education and school situation, including the availability of teachers, the number of required teachers for the nine year comprehensive school, and the available school buildings. A committee under the ministry of education took these municipality characteristics into account when deciding on participation. Once approved, funding for extra teachers and school buildings was provided. Since the implementation of the reform at the municipality level placed economic and organizational demands on the local resources, economic subsidies were given to encourage implementation. These subsidies were granted to level differences between rich and poor municipalities and ensured that implementation was arguably representative across Norway (Lie 1973).

\subsection{The compulsory school reform treatment}

In our empirical setup we treat the compulsory school reform as a natural experiment. Children are assigned to treatment and control groups, in a more or less random fashion, based on their year of birth and municipality of residence. With the treatment defined as exposure to the compulsory school reform, we follow these children into 
later adulthood and compare their cancer mortality rates, overall cancer risk and cancer risks for the most common cancer sites. Any observable cancer differences between the treated and control children can then exclusively be attributed to differences in reform exposure. In order to interpret any estimated reform effect, however, we need to know what the reform treatment actually entails.

The reform introduced three institutional changes to the education system at the same time. The reform increased mandatory education, standardized curriculum and postponed ability tracking. Each of these three changes may have had an impact on the educational attainment of these children, both in quantity and quality. The mandatory increase from seven to nine years of compulsory education, for example, raised the time children spent in school and possibly the skills (relevant to a good health) they have learned there. The standardization of the curriculum likely improved the average level of quality of the schools, in particular the rural areas (Black et al. 2005). The delayed tracking was aimed to raise equality of opportunity; it is unclear, however, how tracking has affected the educational attainment of children. Some studies find that early tracking is beneficial for all students (Duflo et al. 2011). Other studies find a small positive effect of postponed tracking, possibly depending on family background (Meghir and Palme 2005; Pekkarinen et al. 2013).

Additionally, the reform may have induced other changes in the education system affecting the educational outcomes of children (and possibly their later life outcomes as well); among these are the reform-induced changes in teacher quality and classroom composition. The reform increased the demand for teachers due to increased school access. If new and inexperienced teachers are more likely to teach those children affected by the reform, the reform was accompanied with a fall in teacher quality with possible long run consequences (Chetty et al. 2011). Another, typically overlooked, feature of the reform is that the reform changed the classroom composition of children. Since the reform forced all children to stay in school for two additional years, the peer composition of each child individually changed. It is not clear how this affects 
classroom quality. It is possible, for example, that children who would obtain a university degree before the reform do worse had the reform been in effect because of increased exposure to potential dropouts. And reversely, children who would leave school in 7th, 8th or 9th grade before the reform may do better because of increased exposure to more academically orientated children.

The reform effect is thus a composite reform effect on cancer risk, incorporating not only the increase in years of mandatory education, but also the anticipated (and unanticipated) changes in school quality, teacher quality and classroom quality that likely matter for the educational attainment of children. Although our empirical framework is limited in its ability to disentangle the composite reform effect, it is still possible to interpret the composite reform effect in a meaningful way. If the reform improved the quality of education, which is supported by the evidence of the reform on earnings (Aakvik et al., 2010), then our empirical framework gives us reform estimates that measure the effect of education on cancer risk. ${ }^{5}$

\section{Empirical strategy}

We examine three related questions concerning the relationship between educational attainment, the education reform and cancer risk. The first is the extent to which various cancer risks (observed in middle and later adulthood) vary with the educational attainment obtained as teenagers. In particular, we explore how our correlations compare (and contrast) to those reported elsewhere in the medical literature. The second examines the impact of the education reform on educational attainment. And relatedly, the third examines the impact of the education reform on cancer risk. To provide answers to these three questions, which are necessary to determine whether the relationship between education and cancer risk is causal, we estimate

\footnotetext{
${ }^{5}$ Other reform studies outside the health domain have also attributed positive reform effects to more and better schooling. Examples are Meghir and Palme (2005), who looked at the reform effect on earnings; and Black et al. (2005) and Holmlund et al. (2011), who looked at intergenerational reform effects.
} 
three regression models.

The first regression model we have in mind, connects cancer risk with educational attainment in the following way

$$
C A N C E R_{i t m}=\alpha_{0}+\alpha_{1} E D_{i}+\alpha_{2} F E M A L E_{i}+M_{i m} \alpha_{3}+B_{i t} \alpha_{4}+u_{i t m}
$$

The indices $i, t$ and $m$ stand for individual $i$ who is born in year $t$ and lives (at the time of the reform) in municipality $m$. The dependent variable $C A N C E R_{i t m}$ represents a set of relevant cancer risks, which we define in terms of binary cancer risk indicators, measuring whether the individual died of cancer, whether the individual has ever been diagnosed with cancer, and whether the individual has ever been diagnosed with cancer at the most common cancer sites. In this model $C A N C E R_{i t m}$ depends on the educational attainment $E D_{i t m}$, which is the nominal number of years spend in school, gender FEMALE $E_{i}$, municipality of residence $M_{i}$, year of birth $B_{i}$, and the econometric error term $u_{i t m}$, which incorporates all unobserved endowments and other characteristics that may influence cancer risk. The variables $M_{i}$ and $B_{i}$ refer to the full set of municipality and birth year dummies. Because the unobserved endowments are likely correlated with education, the parameter $\alpha_{1}$ measures the correlation between years of education and various cancer risks, conditional on the predetermined control variables (gender, municipality of residence at time of the reform, and birth year).

The second regression model examines the impact of the reform on educational attainment. Since different municipalities adopted the education reform at different times, we can estimate a standard differences-in-differences regression model

$$
E D_{i t m}=\beta_{0}+\beta_{1} R E F O R M_{i t m}+\beta_{2} F E M A L E_{i}+M_{i} \beta_{3}+B_{i} \beta_{4}+v_{i t m}
$$

where education outcome $E D_{i t m}$ depends on whether the individual is exposed to the reformed education system $R E F O R M_{i t m}$, gender $F E M A L E_{i}$, school municipality 
$M_{i}$, year of birth $B_{i}$, and the random error term $v_{i t m}$, which captures those unobserved endowments and characteristics that have an impact on educational attainment. may influence cancer risk. In our model we treat the education reform as our source of exogenous variation in education and assume that $v_{i t m}$ is uncorrelated with $R E F O R M_{t m}$ conditional on the other control variables. The parameter $\beta_{1}$ can therefore be interpreted in a causal fashion, measuring the change in average years of education due to reform exposure.

And finally, the third model examines the impact of the reform on cancer risk. Parallel to the previous regression model, with similar exogeneity assumptions, we estimate a differences-in-differences regression model

$$
C A N C E R_{i t m}=\gamma_{0}+\gamma_{1} R E F O R M_{i t m}+\gamma_{2} F E M A L E_{i}+M_{i} \gamma_{3}+B_{i} \gamma_{4}+w_{i t m}
$$

with the dependent variable switched to cancer risk. The parameter of interest is $\gamma_{1}$, which measures the average effect of the reform on cancer risk, at least for those who are assigned to the reform. A negative $\gamma_{1}$ signals that more educated men and women face lower cancer risks because of more education, and not because of something else.

We apply ordinary least squares (OLS) to estimate the equations (1), (2) and (3). In addition, we estimate these models on split as well as pooled samples of men and women. In case of split samples, we do not control for gender. Standard errors are clustered at the municipality level.

There are three possible pitfalls in interpreting the OLS estimates of the regression models reported above. First, the key assumption in differences-in-differences estimation is that reformed and non-reformed municipalities experience parallel trends; that is, in the absence of the reform the outcome variable should similarly evolve in reformed and non-reformed municipalities. If this assumption is violated, these specifications will give us inconsistent estimates of the reform effect. To relax this assumption, we also estimate the differences-in-differences specifications with 
municipality specific linear time trends included. If the parameter attached to the reform indicator captures the response to the reform, it should be insensitive to inclusion of municipality specific trends.

Second, equations (2) and (3) represent the first stage and reduced form regression models in two stage least squares estimation (2SLS). The main reason for not presenting 2SLS estimates is a questionable exclusion restriction; that is, the reform effect incorporates not only the increase in years of mandatory education, but also changes in school quality, teacher quality and classroom quality.

Third, cancer risks are right censored, which may constitute a censoring bias. As an alternative, we can use Cox proportional hazards regression models to analyze cancer mortality rates and cancer incidence rates (by means of hazard rates) and take right censoring into account. For time to cancer death (diagnosis) we use the following proportional hazard specification

$$
\lambda(D)=\lambda_{m}(D) \cdot \lambda_{t} \cdot \exp \left(\delta_{1} R E F O R M_{i t m}+\delta_{2} F E M A L E_{i}\right),
$$

with exposure time $D$, a municipality specific baseline hazard $\lambda_{m}$, a cohort specific relative risk factor $\lambda_{t}$, and explanatory variables we have defined above. Again, we will run these proportional hazard models on split as well as pooled gender samples.

\section{Data}

The data we use are a combination of multiple administrative registers in Norway. The baseline sample is drawn from the Norwegian Population Register. This register contains information on all Norwegian citizens who were alive in 1954. In our analysis we focus on cohorts affected by the Norwegian education reform based on year of birth and municipality of residence (at the school going age). In the Norwegian Population Register we select reform affected cohorts, born between 1947 and 1958, 
in our sample. ${ }^{6}$ In the 1960 Census, which contains municipality information, we collect information on municipality of residence at the time of the education reform.

Education information comes primarily from the 1970 Census. The Norwegian Education Registry started in 1970; we therefore collect education information from this registry for those who completed their education after 1970. Educational attainment is measured in nominal years of education taken from detailed education classifications.

Cancer information comes from the Norwegian Cancer Registry, which holds records of any cancer diagnosis and, in case of death, whether cancer has been the leading cause. This cancer registry collects individual level data from 1954 to 2007. Reporting to the cancer registry is mandatory (and done by clinicians and pathologists) and the completeness of registrations for solid tumors is close to 100 percent (Cancer Registry of Norway, 2007; Larsen et al., 2009). Information is available on the date of diagnosis, location of the tumor (encoded by ICD-10), stage at diagnosis (metastasis), the date the death certificate was issued (if the patient has died) and whether cancer was the main cause of death.

Table 1 shows the prevalence of cancer mortality, overall cancer incidence, and cancer incidence for the most common cancer types in our sample encoded by the first three digits of the ICD-10 (International Classification of Diseases, 10th revision) codes. Because we work with samples in which the average age when diagnosed with cancer is quite young, the cancer rates are quite low. Yet we see the common cancer patterns (albeit much smaller). Breast cancer is clearly the most common cancer type among women.

\footnotetext{
${ }^{6}$ In case we run regression specifications with municipality specific trends, we extend the sample with pre-reform cohorts born between 1942 and 1946. This allows us to approximate a linear trend prior to reform implementation in municipaties that adopted the reform early.
} 
Table 1. Descriptive statistics - Incidence of cancer

\begin{tabular}{lccc}
\hline & All & Women & Men \\
\hline Cancer death & 0.0166 & 0.0181 & 0.0152 \\
Cancer type & 0.0650 & 0.0775 & 0.0532 \\
- All & 0.0056 & 0.0056 & 0.0057 \\
- Colorectal & 0.0045 & 0.0040 & 0.0049 \\
- Lung & 0.0075 & 0.0082 & 0.0068 \\
- Skin & 0.0129 & 0.0264 & $<.0001$ \\
- Breast & 0.0047 & 0.0097 & 0.0072 \\
- Cervical & 0.0037 & & 0.0042 \\
- Prostate & 0.0022 & 0.0044 & 0.0063 \\
- Testicular & 0.0054 & & 637,142 \\
- Leukemia & & 602,629 & \\
Observations & $1,239,771$ & & \\
\hline
\end{tabular}

\section{Results}

To quantify the extent to which education and cancer risk are causally linked, we estimate a variety of regression models set out in equations (1), (2) and (3).

\subsection{The association between education and cancer risk}

Tables 2 contains simple estimates of the relationship between education (measured in years) on cancer risks controlling for a few demographic variables we consider exogenous (gender, municipality and year of birth). Results are presented for various cancer risks: cancer mortality, overall cancer risk and cancer risks for the most common cancer sites, including colorectal cancer, lung cancer, skin cancer, leukemia, breast and cervical cancer for women, and prostate and testicular cancer for men. In column 1 we report the OLS results of equation (1) for the full sample of men and women who are somewhere between 50 and 60 years old. We find that more educated men and women face significantly lower risks for any cancer. The estimated coefficient on education shows how education covaries with the probability of having died of any cancer is about -0.0016 [9 percent], where to get an idea about magnitude, we also report the relative percentage change in the sample average cancer rate associated 
with one extra year of education between brackets. The estimated coefficient on the probability of being diagnosed with any cancer is about -0.0012 [2 percent]. Although these coefficients appear small, they are highly significant. If we turn to the four most common sites of cancer shared by men and women, we find that these coefficients are considerably smaller and not always negative. Men and women with more education face significantly lower risks of developing lung cancer (-0.0007 [16 percent]). In contrast, men and women with more education face significantly higher risks of skin cancer $(0.00038$ [5 percent] $)$.

Table 3 contains the same set of estimates for men and women separately. In column 1 we find again decreased cancer risks for all cancers among more educated men as well as among more educated women. There are no apparent gender differences between men and women. The regression association between education and the cancer mortality rate is -0.0015 [10 percent] for men, and -0.0018 [9 percent] for women. The association with the likelihood of a cancer diagnose is -0.0009 [2 percent] for men, and -0.0013 [2 percent] for women. The correlations between education and cancer risk at common cancer sites vary in sign. Among men, the association between education and cancer risk is significantly negative for lung cancer (-0.0008 [17 percent]), but significantly positive for skin cancer (0.0004 [6 percent]) and prostate cancer (0.0004 [5 percent]). Among women, the association of education and cancer risk for is significantly negative for colorectal cancer (-0.0011 [2 percent]), lung cancer $(-0.0007$ [15 percent] $)$ and cervical cancer (-0.0007 [15 percent]), but significantly positive for skin cancer (0.0003 [4 percent]) and breast cancer (0.0006 [4 percent]).

These results are comparable to many of the estimates that have appeared in the medical literature, which ignore the correlation between the individual's educational attainment, endowments and other unobserved characteristics. 


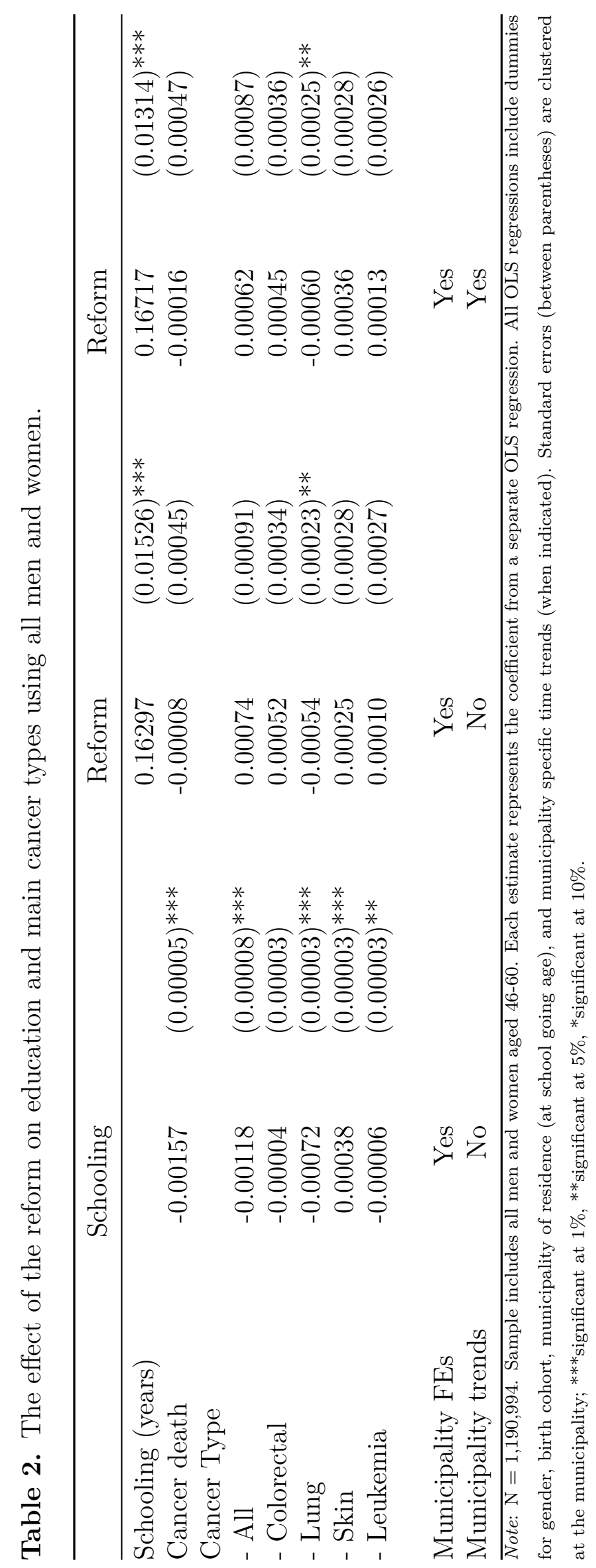




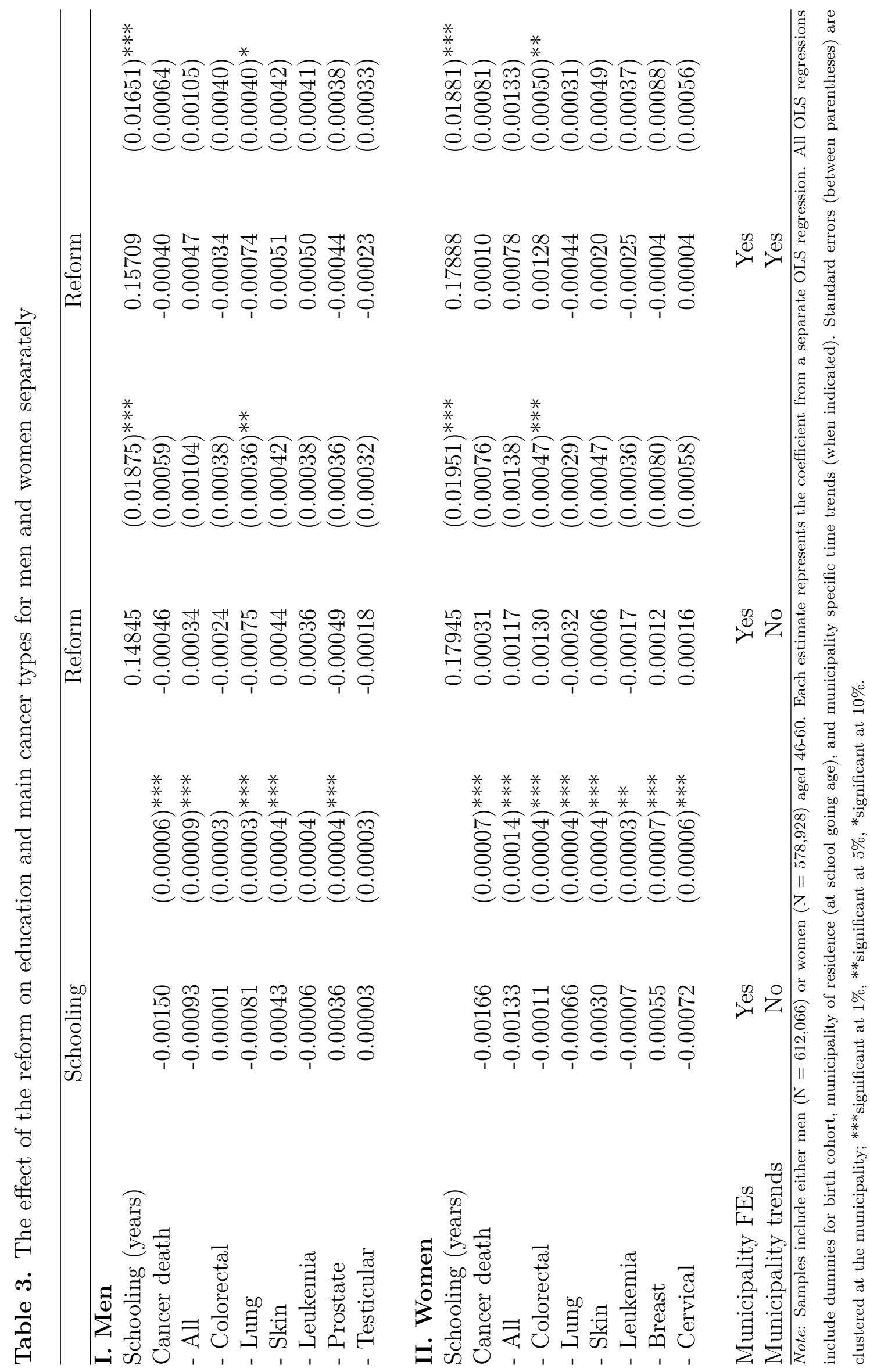




\subsection{The effect of the reform on education}

Table 2 also contains the estimates of the impact of the compulsory school reform on educational attainment, measured in years, for the whole sample of men and women. Table 3 contains the same set of reform estimates for men and women separately. In column 2 we present the OLS estimates of $\beta_{1}$, which come from the differences-in-differences specification (2) without municipality specific linear time trends. In column we present the same OLS estimates using the same specifications with municipality specific linear time trends.

The impact of the reform on educational attainment turns out to be significant and positive. In column 2 we find that the effect of the school reform raised the average number of years spend in school by about 0.16 years. This effect is primarily driven by the increased education of those men and women who would have dropped out in either 7 th or 8 th grade in the absence of the reform. Note that our reform estimates are remarkably stable across different samples and different specifications. We obtain very similar reform estimates when we look at men and women separately. We obtain very similar reform estimates with and without municipality specific trends. And we obtain reform estimates very similar to those reported in Black et al. (2005).

Figure 2 displays the effect of the reform on average years of education, after taking out municipality and birth year fixed effects. Time zero represents the year of reform implementation. Comparing the average years of education in pre- and post-reform years, we can clearly see that the reform is fully responsible for the large and discontinuous jump in the educational attainment of men and women.

\subsection{The effect of the reform on cancer risk}

To evaluate the impact of the educational reform on cancer risk, we run the same differences-in-differences regressions with the dependent variable switched to cancer risks. Tables 2 and 3 report these differences-in-differences estimates of equation 


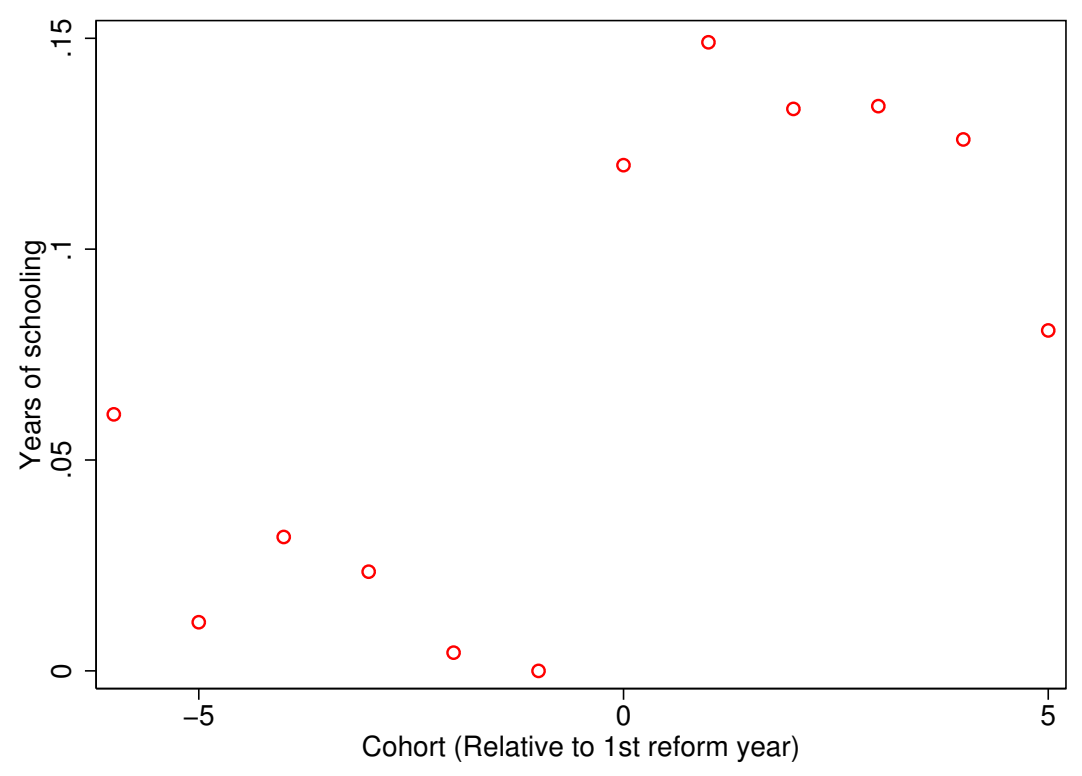

Figure 2. First stage

(3) in the same format as before. Assuming that our procedure takes account of the unobserved endowments, the reform estimates are driven by the causal effect of education on cancer risk.

We first consider cancer risk in terms of cancer mortality and overall cancer risk. Our results reveal that the compulsory schooling reform had little if any effect on cancer mortality (from any cancer site). All the reform coefficients we estimate are close to zero and statistically insignificant, regardless of whether we run regressions on pooled gender samples, on split gender samples, or with and without municipality specific trends. When we replace cancer mortality with overall cancer risk, measuring whether someone has ever been diagnosed with cancer (from any cancer site), our results remain small, statistically insignificant and change little across the different samples and specifications; the estimated effect of the reform on overall cancer risk is marginally negative for men $(-0.0005$ [1 percent] $)$ and marginally positive for women (0.0011 [1 percent]). Again, the number between brackets represents the relative percentage change in the sample average cancer rate associated with reform exposure.

We next consider cancer risk in terms of cancer risk by cancer site for the most common cancer sites. Our results indicate that the marginal reform effects on overall 
cancer risks mask important gender differences at different cancer sites. For men we find that the reform significantly lowered the risk of lung cancer; the estimated effect of the reform on lung cancer risk is -0.0007 [15 percent]. For women we find that the reform caused a significant rise in colorectal cancer; the estimated effect of the reform on lung cancer risk is 0.0013 [23 percent]. While these two reform effects are significant and sizeable, all the other reform effects we estimate are much smaller (in terms of relative risks) and not significantly different from zero. It thus seems that the small and weak reform effects we find for the overall cancer risks carry over to most of the specific cancer risks as well.

\subsection{Censored cancer risks}

The cancer risk variables we have used in the analysis thus far are binary cancer risk indicators, measuring among others whether men and women have been diagnosed with cancer somewhere between 1954 to 2007, regardless of how old these men and women are. This means that we measure the risks of detecting cancer for the oldest cohort up to the age of 60 , whilst for the youngest cohort up to the age of 49 . This is a problem of right censoring; that is, we miss out on all those cancer risks for men and women younger than 60 in 2007 who may develop and/or die from cancer later on in life.

One simple procedure to address the problem of (right) censoring is to estimate proportional hazard regression models. Table 4 contains the hazard rates for cancer incidence taken from Cox proportional hazard regression models estimated on the full sample consisting of men and women. Table 5 contains the same set of hazard estimates for men and women separately. Hazard rates lower than one indicate a protective effect of either education or reform. And reversely, hazard rates larger than one indicate a harmful effect. In column 1 we present the hazard rates for cancer incidence associated with years of education. The hazard results suggest that education matters. In most specifications, education leads to a small but highly 


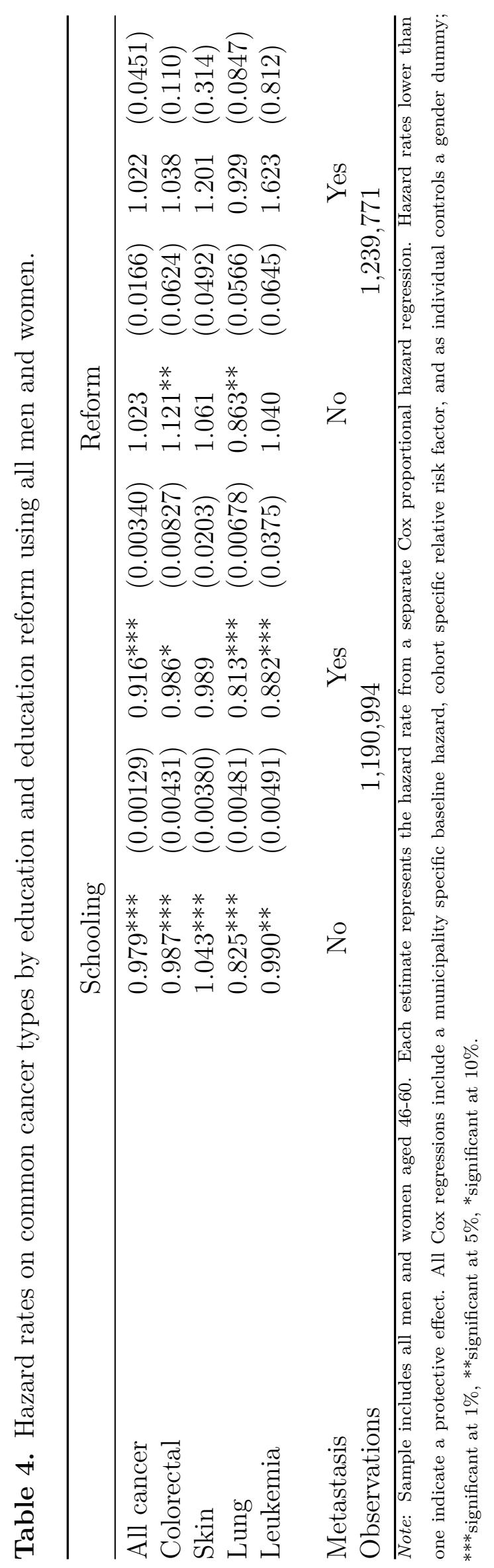




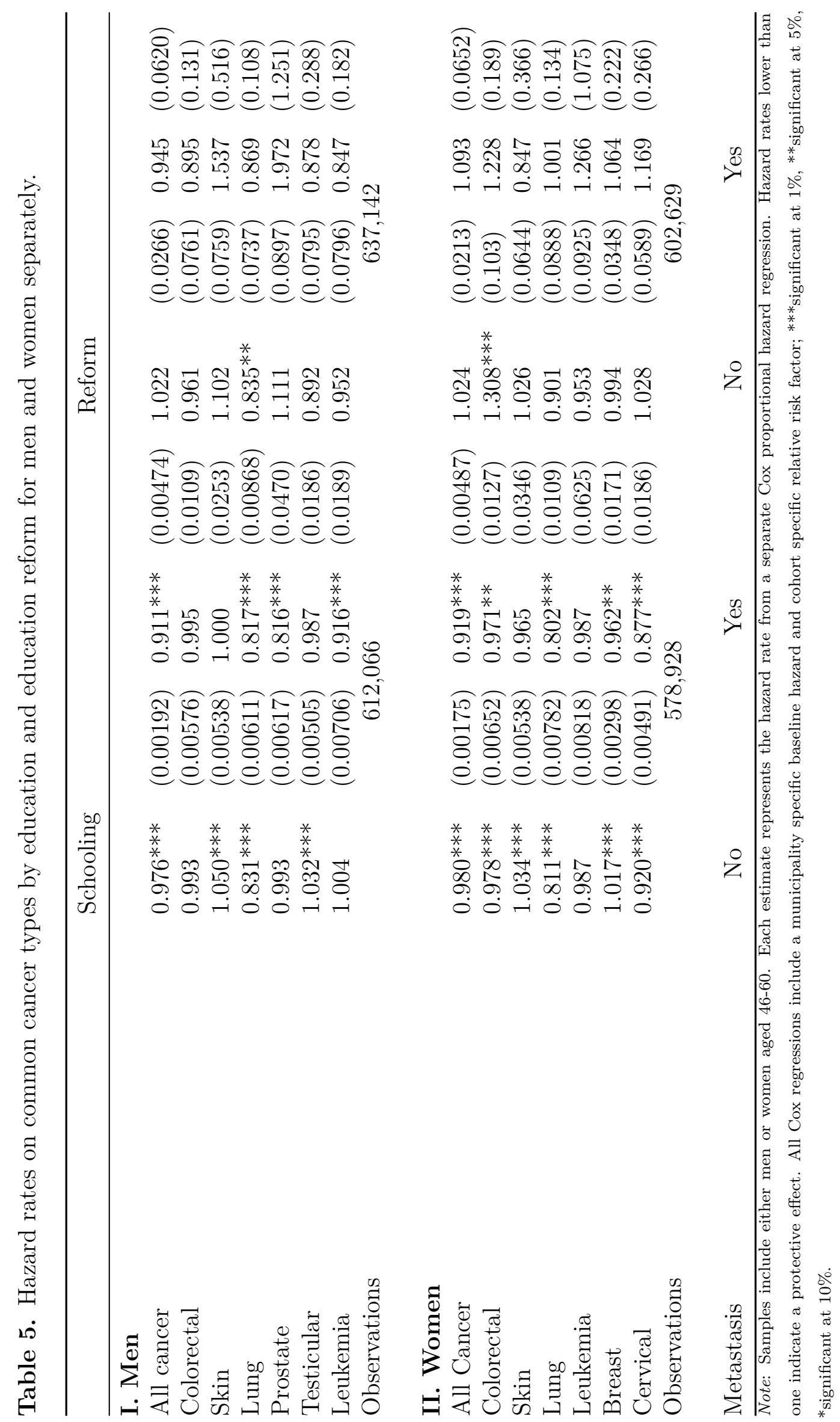


significant reduction in cancer risk. This is particularly true for lung cancer: the hazard of 0.825 (in column 1 of Table 4) suggests that one extra year of education is associated with a lower overall risk of detecting lung cancer by 17.5 percent (up to the age of 60 years old). In column 3 we present the hazard rates for cancer incidence by reform exposure. In almost all most specifications, the cancer hazards associated to the reform are not significantly different from one, suggesting that the effect of the compulsory school reform is relatively small and not significant from zero. There are again two noticeable exceptions. For men we find a lung cancer hazard of 0.835 (reported in column 3 of Table 5), which indicates that the reform had a significantly large and protective impact on lung cancer risk. For women we find a colorectal cancer hazard of 1.308 (also reported in column 3 of Table 5), which indicates that the reform effect is significant and strong, but harmful. Overall, the hazards reveal a very comparable cancer pattern suggesting that censoring and the entailing bias is not our biggest concern.

\subsection{Malignant cancer risks}

The severity of the cancer depends not only on where the tumor is located, but also on whether the cancer has spread to other locations (or metastasize). A malignant cancer is defined by its ability to metastasize. In this section we ask ourselves whether education and reform effects change when we consider the cancer risks of the more malignant cancers, which are more likely to cause health problems.

Tables 4 and 5 show how malignant cancer risks (measured by means of hazard rates) vary by education (measured in years) and reform exposure. We use the same format as before. In column 2 we present the hazard rates for malignant cancer incidence associated with years of education. The hazard rates, while imprecisely estimated, are all smaller than one (except malignant skin cancer for men), suggesting that more educated men and women are less likely diagnosed with cancer that has spread out to other locations. They are also smaller than the hazard rates for all 
cancers, including benign and malignant cancers (reported in column 1 of the same table). The difference in hazards makes sense if we expect that more educated men and women live healthier lives and detect cancer earlier. In column 4 , however, we show that most of the hazard rates for men and women exposed to the reform are considerably larger than one, suggesting that education is not the protective driver behind malignant cancer risks. Bear in mind, though, that the hazard rates are rather imprecisely estimated to draw firm conclusions about the weak link between education and malignant cancer risk.

\subsection{What is the effect of education on cancer risk?}

Our main finding is that education has little if any impact on cancer risk. This holds for all cancer sites together as well as the most common cancer sites in isolation, with two exceptions. The compulsory school reform lowered the risk of lung cancer for men, but increased the risk of colorectal cancer for women. It is important to understand why this is, and where these gender differences come from. In this section we speculate about possible explanations.

On the protective effect of education on lung cancer risk most medical scientists agree. And indeed, the vast majority of empirical studies report a negative correlation between education (or a socioeconomic variation thereof) and lung cancer risk (Sidorchuk et al. 2009). These correlations are typically interpreted as evidence that poor health behavior, and harmful smoking in particular, is the leading cause of lung cancer (Peto et al. 2000). Of course, for this to be true we must assume that education causes men to smoke less. Evidence on this includes the work of De Walque (2007), who finds a negative effect of education on cigarette consumption (using the military draft lottery as a natural experiment). The weaker effect we find for women is not unexpected; at the time of the reform, women smoked considerably less than men (Lund and Lindbak 2007).

On the harmful effect of education on colorectal cancer risk, however, medical 
scientists disagree. In fact, the medical evidence is mixed. Some empirical studies report positive correlations between education and colorectal cancer risk (Van Loon et al. 1995; Tavani et al. 1999; Weiderpass and Pukkala 2006; Weiderpass and Pukkala 2006; Leufkens et al. 2012), while others report zero or negative correlations (Whynes et al. 2003; Palmer and Schneider 2005; Aarts et al. 2010). In interpreting these correlations, regardless of their size and sign, diet is often mentioned as one of the causative factors. Perhaps we find this harmful effect because the Norwegian reform changed the diet of women living in rural areas, who began to consume more meat and less home grown grains, fruits and vegetables. But there may be other causative factors too. Perhaps we find a harmful effect because of increased stress levels. If reform exposed mothers choose to work more, it is possible that the increase in working hours, combined with care of children, causes stress in mothers. ${ }^{7}$ Recent work by Baker et al. (2008) shows that the combination of work and care is indeed stressful for mothers.

\section{Conclusions}

There is an extensive medical literature that finds strong negative associations between education and cancer risk. Important questions about the causal effect of education on cancer risk, however, remain largely unresolved. In this paper we try to provide some answers; that is, we investigate whether education has a protective effect on cancer risk. Our strategy uses the reform of the Norwegian education system, which has been implemented in different municipalities at different times, to establish causal effects of education on various cancer risks faced in middle and late adulthood. Our main finding is that education has little, if any, impact on cancer risk. This holds for all cancer sites together as well as the most common cancer

\footnotetext{
${ }^{7}$ Another explanation is that more education improves detection skills, which in turn may raise the incidence levels of colorectal cancer among more educated women. We find, however, little support for this view. Table 5 shows that the colorectal cancer hazards for women hardly change when we move to the more malignant cancers, suggesting that for colorectal cancer more education is more harmful than protective.
} 
sites in isolation, with two exceptions. Our estimates consistently show that the education reform lowered the risk of lung cancer for men, but increased the risk for colorectal cancer for women. Equally important is our finding that almost all the associations we estimate between education, cancer mortality and cancer risk, aggregated across all cancer sites, are statistically significant and negative. These associations are comparable to most of the associations reported elsewehere in the medical literature. It thus seems that unobserved endowments play a crucial role in explaining the educational gradient in cancer risk.

When interpreting these results, four caveats should be kept in mind. First, the reform estimates are all small but sometimes relatively imprecisely estimated, with only significant reform effects estimates for lung and colorectal cancer. Although this suggests some caution in the interpretation, our reform estimates rule out large gains in cancer risk from more and better education. Second, the cancer outcomes studied here relate to cancer risks up to 60 years old. To the extent that risks of developing or dying from cancer after the age of 60 are driven by differences in education, our estimates do not capture this. Third, our results apply to Norway and may not generalize to other countries that have more costly education and health care. And last, the reform estimates we present come from children who are affected by the compulsory school reform; that is, children who were forced to stay in school for at least one or two more years because of the reform. This means that our estimates do not necessarily measure potential protective gains of, for example, a college degree. A recent study by Buckles et al. (2013) considers the impact of college education on, among others, cancer mortality among US men. Using military draft lotteries in the 70 s as instrument for college education, they find that large protective effects on cancer mortality (and on lung cancer mortality in particular). A comparable exercise using college opening reforms in Norway could be enlightening but is left for future research. 


\section{References}

Aakvik, A., Salvanes, K. G., and Vaage, K. (2010). Measuring heterogeneity in the returns to education using an education reform. European Economic Review, 54(4):483-500.

Aarts, M. J., Lemmens, V. E., Louwman, M. W., Kunst, A. E., and Coebergh, J. W. W. (2010). Socioeconomic status and changing inequalities in colorectal cancer? a review of the associations with risk, treatment and outcome. European Journal of Cancer, 46(15):2681-2695.

Albano, J. D., Ward, E., Jemal, A., Anderson, R., Cokkinides, V. E., Murray, T., Henley, J., Liff, J., and Thun, M. J. (2007). Cancer mortality in the united states by education level and race. Journal of the National Cancer Institute, 99(18):1384-1394.

Baker, M., Gruber, J., and Milligan, K. (2008). Universal childcare, maternal labor supply, and family well-being. Journal of Political Economy, 116(4):709-745.

Black, S. E., Devereux, P. J., and Salvanes, K. G. (2005). Why the apple doesn't fall far: Understanding intergenerational transmission of human capital. American economic review, 95(1):437-449.

Buckles, K., Hagemann, N. A., Malamud, O., and Morrill, N. M. (2013). The effect of college education on mortality.

Chetty, R., Friedman, J. N., and Rockoff, J. E. (2011). The long-term impacts of teachers: Teacher value-added and student outcomes in adulthood. Technical report, National Bureau of Economic Research.

Clark, D. and Royer, H. (2010). The effect of education on adult health and mortality: Evidence from britain. Technical report, National Bureau of Economic Research. 
Cutler, D. M. and Lleras-Muney, A. (2010). Understanding differences in health behaviors by education. Journal of health economics, 29(1):1-28.

De Walque, D. (2007). Does education affect smoking behaviors?: Evidence using the vietnam draft as an instrument for college education. Journal of health economics, 26(5):877-895.

DePinho, R. A. (2000). The age of cancer. Nature, 408(6809):248-254.

Duflo, E., Dupas, P., and Kremer, M. (2011). Peer effects, teacher incentives, and the impact of tracking. American Economic Review, 101(4):1739-1774.

Grossman, M. (2006). Education and nonmarket outcomes. Handbook of the Economics of Education, 1:577-633.

Holmlund, H., Lindahl, M., and Plug, E. (2011). The causal effect of parents' schooling on children's schooling: a comparison of estimation methods. Journal of Economic Literature, 49(3):615-651.

Hussain, S., Lenner, P., Sundquist, J., and Hemminki, K. (2008). Influence of education level on cancer survival in sweden. Annals of oncology, 19(1):156-162.

Leufkens, A. M., Van Duijnhoven, F. J., Boshuizen, H. C., Siersema, P. D., Kunst, A. E., Mouw, T., Tjønneland, A., Olsen, A., Overvad, K., Boutron-Ruault, M.-C., et al. (2012). Educational level and risk of colorectal cancer in epic with specific reference to tumor location. International Journal of Cancer, 130(3):622-630.

Lie, S. S. (1973). Regulated social change: a diffusion study of the norwegian comprehensive school reform. Acta Sociologica, pages 332-350.

Lindbekk, T. (1993). School reforms in norway and sweden, and the redistribution of educational attainments. Scandinavian Journal of Educational Research, 37(2):129149. 
Lleras-Muney, A. (2005). The relationship between education and adult mortality in the united states. Review of Economic Studies, 72(1):189-221.

Lund, M. and Lindbak, R. (2007). Norwegian tobacco statistics 1973-2006. Norwegian Institute for Alcohol and Drug Research. Oslo.

Meghir, C. and Palme, M. (2005). Educational reform, ability, and family background. The American Economic Review, 95(1):414-424.

Meghir, C., Palme, M., and Simeonova, E. (2012). Education, health and mortality: Evidence from a social experiment. Technical report, National Bureau of Economic Research.

Monstad, K., Propper, C., and Salvanes, K. G. (2008). Education and fertility: Evidence from a natural experiment. Scandinavian Journal of Economics, 110(4):827-852.

Mouw, T., Koster, A., Wright, M. E., Blank, M. M., Moore, S. C., Hollenbeck, A., and Schatzkin, A. (2008). Education and risk of cancer in a large cohort of men and women in the united states. PLoS One, 3(11):e3639.

Oreopoulos, P. (2006). Estimating average and local average treatment effects of education when compulsory schooling laws really matter. The American Economic Review, pages $152-175$.

Palmer, R. C. and Schneider, E. C. (2005). Social disparities across the continuum of colorectal cancer: a systematic review. Cancer Causes \& Control, 16(1):55-61.

Pekkarinen, T., Uusitalo, R., and Pekkala Kerr, S. (2013). School tracking and development of cognitive skills. Journal of Labor Economics, 31(3):577-602.

Peto, R., Darby, S., Deo, H., Silcocks, P., Whitley, E., and Doll, R. (2000). Smoking, smoking cessation, and lung cancer in the uk since 1950: combination of national statistics with two case-control studies. Bmj, 321(7257):323-329. 
Sidorchuk, A., Agardh, E. E., Aremu, O., Hallqvist, J., Allebeck, P., and Moradi, T. (2009). Socioeconomic differences in lung cancer incidence: a systematic review and meta-analysis. Cancer Causes \& Control, 20(4):459-471.

Tavani, A., Fioretti, F., Franceschi, S., Gallus, S., Negri, E., Montella, M., Conti, E., and La Vecchia, C. (1999). Education, socioeconomic status and risk of cancer of the colon and rectum. International journal of epidemiology, 28(3):380-385.

Van Loon, A., Van den Brandt, P., and Golbohm, R. (1995). Socioeconomic status and colon cancer incidence: a prospective cohort study. British journal of cancer, $71(4): 882$.

Weiderpass, E. and Pukkala, E. (2006). Time trends in socioeconomic differences in incidence rates of cancers of gastro-intestinal tract in finland. BMC gastroenterology, $6(1): 41$.

Whynes, D., Frew, E., Manghan, C., Scholefield, J., and Hardcastle, J. (2003). Colorectal cancer, screening and survival: the influence of socio-economic deprivation. Public health, 117(6):389-395. 